\title{
Consumo e digestibilidade aparente em novilhas alimentadas com dietas contendo cana-de-açúcar tratada com óxido de cálcio ${ }^{1}$
}

\section{Gleidson Giordano Pinto de Carvalho², Rasmo Garcia ${ }^{3,7}$, Aureliano José Vieira Pires ${ }^{4,7}$, Robério Rodrigues Silva ${ }^{4}$, Hermógenes Almeida Santana Júnior ${ }^{5}$, Alyson Andrade Pinheiro ${ }^{6}$, Fabrício Barcelar Lima Mendes ${ }^{5}$, Leandro Sampaio Oliveira Ribeiro ${ }^{5}$}

\author{
${ }^{1}$ Projeto financiado pelo CNPq. \\ 2 Doutorando em Zootecnia, UFV, Viçosa, MG. \\ 3 Universidade Federal de Viçosa, UFV, Viçosa, MG. \\ 4 Universidade Estadual do Sudoeste da Bahia, UESB, Itapetinga, BA. \\ ${ }^{5}$ Graduando em Zootecnia/UESB, Itapetinga, BA. \\ ${ }^{6}$ Doutorando em Zootecnia/UEM, Maringá, PR. \\ 7 Pesquisador do CNPq.
}

RESUMO - Desenvolveu-se este estudo para avaliar o consumo e a digestibilidade aparente dos nutrientes em novilhas alimentadas com dietas contendo cana-de-açúcar tratada com óxido de cálcio. Avaliou-se também a eficiência de predição do consumo de matéria seca e do valor energético dos alimentos. Utilizaram-se 20 novilhas mestiças Holandês-Zebu com peso corporal médio inicial de $200 \mathrm{~kg}$, distribuídas em delineamento inteiramente ao acaso, com quatro dietas e cinco repetições. As dietas foram formuladas para ser isoproteicas e fornecer $14 \%$ de proteína bruta e foram compostas de $71 \%$ de cana-de-açúcar tratada com 0; 0,75; 1,5 ou 2,25\% de óxido de cálcio (com base na matéria natural) e corrigida com 1\% da mistura ureia e sulfato de amônio (9:1) e 29\% de concentrado. Os consumos de matéria seca (MS), matéria orgânica (MO), extrato etéreo (EE), fibra em detergente neutro (FDN), fibra em detergente neutro corrigida para cinzas e proteína (FDNcp), fibra em detergente neutro indigestível (FDNi), carboidratos totais (CT), carboidratos não-fibrosos corrigidos para cinza e proteína (CNFcp) e nutrientes digestíveis totais (NDT), em kg/dia, não foram afetados pela adição de óxido de cálcio à cana-de-açúcar. Os consumos de MO, FDN, FDNcp e NDT (\% PV) reduziram linearmente com as doses de óxido de cálcio. As digestibilidades de MO, FDN, FDNcp, carboidratos totais e CNFcp e o teor de NDT das dietas não foram afetados. Entretanto, o tratamento da cana-de-açúcar com óxido de cálcio provocou redução na digestibilidade da MS e PB. As equações propostas pelo National Research Council subestimaram os consumos de MS e NDT e de PB e CNF digestíveis e superestimaram os de FDN digestível. O tratamento da cana-açúcar com óxido de cálcio não melhora o consumo nem a digestibilidade dos nutrientes em novilhas. As equações propostas pelo National Research Council não são eficientes para estimar o consumo de MS e o valor energético de alimentos nas condições experimentais.

Palavras-chave: aditivo químico, matéria seca, valor nutritivo

\section{Intake and apparent digestibility of heifers fed diets containing sugar cane treated with calcium oxide}

\begin{abstract}
This study was developed to evaluate the intake and apparent digestibility of nutrients in dairy heifers fed diets containing sugar cane treated with calcium oxide $(\mathrm{CaO})$. It was also evaluated the prediction efficiency of dry matter intake and food energy value. Twenty Holstein-zebu crossbred dairy heifers, at $200 \mathrm{~kg}$ average initial body weight were used, distributed in a completely randomized design, with four diets and five repetitions. The diets were formulated to be isoprotein and to supply $14 \%$ crude protein and they were composed of $71 \%$ sugar cane treated with $0 ; 0.75 ; 1.5$ or $2.25 \%$ calcium oxide (in natural matter basis) corrected with $1 \%$ of urea and ammonium sulfate (9:1) and $29 \%$ of concentrate. Intakes of dry matter (DM), organic matter $(\mathrm{OM})$, ether extract (EE), neutral detergent fiber (NDF), neutral detergent fiber corrected for ash and protein (NDFap), indigestible neutral detergent fiber (iNDF), total carbohydrates (TC), non-fibrous carbohydrates corrected for ash and protein (NFCap) and total digestible nutrients (TDN) (\% BW) were linearly reduced with calcium oxide doses. Digestibilities of OM, NDF, NDFap, total carbohidrates and NFCap and TDN content in the diets were not affected. However, hydrolyses of sugar cane with calcium oxide caused reduction in the digestibility of DM and CP. The equations proposed by National Research Council underestimated intakes of DM and TDN and digestible CP and NFC and overestimated intakes of digestible NDF. Hydrolyses of sugar cane with calcium oxide do not improve intake of nutrients neither digestibility of nutrients in dairy heifers. The equations proposed by National Research Council are not efficient to estimate the DM intake and food energy value in experimental conditions.
\end{abstract}

Key Words: chemical additive, dry matter, nutritive value 


\section{Introdução}

A busca por fontes alternativas de menores custos para manter o desempenho satisfatório em novilhas, é uma opção para a nutrição adequada desses animais. Entre as alternativas existentes, o fornecimento de canade-açúcar com ureia e enxofre tem mostrado vantagens econômicas em relação a outros volumosos, como capineiras, fenos e silagens (Nússio et al., 2000).

O crescente uso da cana-de-açúcar na alimentação animal tem sido associado a alguns atributos, como a alta produtividade de massa verde (mais de $120 \mathrm{t} / \mathrm{ha}$ ), o baixo custo por unidade de matéria seca (MS), a manutenção do valor nutritivo até seis meses após a maturação e o período de colheita coincidente com o período de escassez de forragem nas pastagens (Silva, 1993). Além disso, esses fatores, aliados à facilidade de obtenção de mudas e plantio, e a possibilidade de se atingir boas taxas de ganho de peso, têm atraído pecuaristas ao uso da cana-de-açúcar como fonte de alimento volumoso (Nussio et al., 2003).

Apesar de inúmeras vantagens, a cana-de-açúcar apresenta elevados teores de fibra de baixa digestibilidade, o que pode provocar redução no consumo de nutrientes pelo animal, em decorrência do decréscimo na taxa de passagem (Prado \& Moreira, 2002). Diversas alternativas têm sido propostas para potencializar o uso da cana-de-açúcar na alimentação de ruminantes, entre elas, o uso de aditivos químicos para o tratamento de volumosos.

A dificuldade de se avaliar a disponibilidade energética e a importância de se conhecer o conteúdo de energia dos alimentos têm levado ao desenvolvimento de métodos para estimar o conteúdo de energia disponível (Valadares Filho et al., 2003). O NRC (2001) propõe um sistema de equações somativas que considera cada fração do alimento, para estimar os nutrientes digestíveis totais. Rocha Júnior et al. (2003), entretanto, comentaram que a predição da energia nos alimentos nas condições tropicais utilizando esse sistema de equações, principalmente para a digestibilidade da FDN, deve ser avaliada antes da recomendação dessas equações.

Desenvolveu-se este estudo para determinar o consumo e a digestibilidade aparente dos nutrientes em novilhas mestiças alimentadas com dietas contendo cana-deaçúcar tratada com diferentes doses de óxido de cálcio e avaliar a aplicabilidade do sistema de equações proposto pelo NRC (2001) para estimar o consumo de nutrientes nas condições tropicais.

\section{Material e Métodos}

O experimento foi conduzido no Laboratório de Animais e no Laboratório de Forragicultura e Pastagens da Universidade Estadual do Sudoeste da Bahia, no Campus de Itapetinga, Bahia. Foram utilizadas 20 novilhas mestiças Holandês-Zebu (3/4 Gir × Holandês) com peso corporal médio inicial de $200 \mathrm{~kg}$, distribuídas em delineamento experimental inteiramente casualizado, com cinco repetições.

Os animais foram alojados em baias individuais cobertas, com piso de concreto e providas de cocho individual de concreto para alimentação e bebedouro automático, comum a duas baias, onde foram alimentados com de cana-deaçúcar (71\%) hidrolisada com óxido de cálcio nas doses de 0; 0,75; 1,5 e 2,25\% e concentrado, 29\% (Tabela 1).

A cana-de-açúcar sem óxido de cálcio foi desintegrada e fornecida no momento do oferecimento das dietas, todos os dias, pela manhã e pela tarde. A cana-de-açúcar acrescida de óxido de cálcio foi processada em máquina desintegradora estacionária, pesada e espalhada em piso de alvenaria e tratada com o aditivo nas doses descritas anteriormente. As doses de óxido de cálcio foram aplicadas à cana-de-açúcar na base da matéria natural, sem diluição em água, e em seguida foi amontoada e fornecida aos animais após 24 horas de armazenamento. Durante todo o período de tratamento (24 horas) da cana-de-açúcar, foi realizado o monitoramento da temperatura (Figura 1).

A cana-de-açúcar com e sem óxido de cálcio (Tabela 2), no momento do fornecimento aos animais, foi corrigida com 1\% da mistura ureia/sulfato de amônio (9:1) na base da matéria natural. Nesse procedimento, a ureia foi previamente pesada de acordo com a quantidade de cana estimada para o consumo dos animais, diluída em água (mantendo sempre a relação de 1 kg de uréia/4litros de água) e aplicada à canade-açúcar com o auxílio de um regador. As dietas (Tabela 3) foram calculadas para ser isoproteicas (14\% de PB) e conter nutrientes suficientes para ganho de peso de 0,6 kg/dia (NRC, 2001).

Tabela 1 - Composição percentual do concentrado e da dieta

\begin{tabular}{lcc}
\hline Ingrediente & Concentrado (\% na MS) & Dieta (\% na MS) \\
\hline Cana de açúcar $^{1}$ & - & 71,0 \\
Fubá de milho & 54,8 & 15,9 \\
Farelo de soja & 39,4 & 11,4 \\
Calcário calcítico & 2,0 & 0,59 \\
Fosfato bicálcico & 1,5 & 0,46 \\
Mistura mineral $^{2}$ & 2,3 & 0,65 \\
\hline
\end{tabular}

1 Cana-de-açúcar tratada com óxido de cálcio $(0 ; 0,75 ; 1,5 ;$ ou $2,25 \%$ na MN) e adicionada de $1 \%$ da mistura uréia + sulfato de amônio (9:1) (\%MN).

2 Quantidade por kg do produto: Ca - 175 g; P - 60 g; Na - 107 g; Mg - 5 g; S 12 g; Co - 70 mg; Cu - 1200 mg; I - 70 mg; Mn - 1000 mg; Ni - 30 mg; Se - 18 mg; $\mathrm{Zn}-4.000 \mathrm{mg}$; Fe - $14.000 \mathrm{mg}$ 


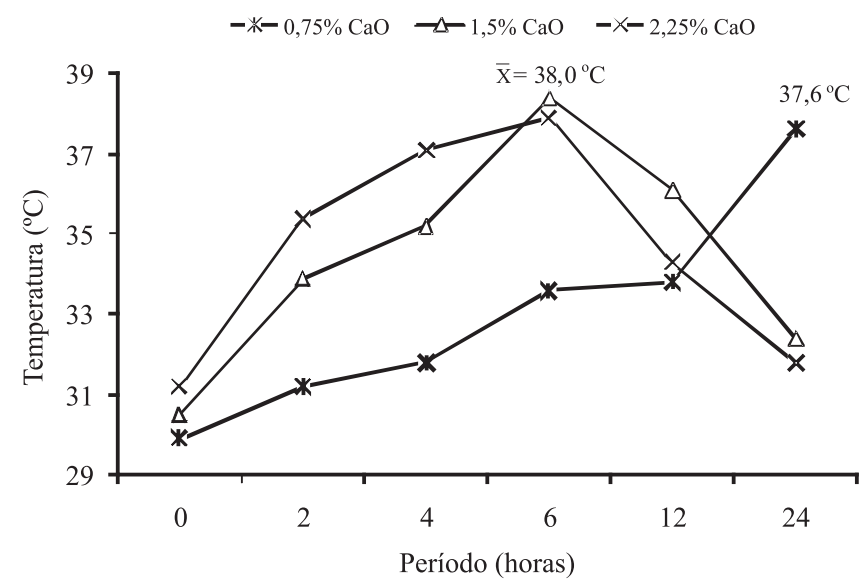

Figura 1 - Temperatura média $\left({ }^{\circ} \mathrm{C}\right)$ da cana-de-açúcar tratada com óxido de cálcio (CaO, \% na MN) em 24 horas.

O experimento teve duração de 21 dias, sendo 14 destinados à adaptação dos animais e sete de coleta. Os alimentos foram fornecidos à vontade, duas vezes ao dia, às $7 \mathrm{~h} 30$ e às $15 \mathrm{~h} 30$, e ajustados de forma a manter as sobras em torno de 5 a $10 \%$ do fornecido, com água permanentemente à disposição dos animais. Durante todo o experimento os alimentos oferecidos foram registrados diariamente. Durante o período de coleta, 15ํㅡ ao $21^{\circ}$ dia, amostras dos volumosos, concentrado e das sobras de cada animal foram coletadas diariamente, acondicionadas em sacos plásticos e armazenadas em freezer. Os animais foram pesados no início e no final do experimento, para estimar o consumo de nutrientes em percentagem do peso vivo.

Amostras dos volumosos, concentrados e sobras de cada animal foram pré-secas em estufa com ventilação forçada a $60^{\circ} \mathrm{C}$ e moídas em moinho de faca (peneira com crivos de $1 \mathrm{~mm}$ ) para posteriores análises químicas bromatológicas.

As análises de matéria seca (MS), matéria orgânica (MO), proteína bruta (PB), extrato etéreo (EE), fibra em detergente neutro (FDN), fibra em detergente ácido (FDA), proteína insolúvel em detergente neutro (PIDN), proteína insolúvel em detergente ácido (PIDA) celulose, hemicelulose e lignina $\left(\mathrm{H}_{2} \mathrm{SO}_{4} 72 \% \mathrm{p} / \mathrm{p}\right)$ foram realizadas segundo procedimentos descritos em Silva \& Queiroz (2002). O teor de fibra em detergente neutro corrigido para cinzas e proteína foi realizado segundo recomendações Licitra et al. (1996) e Mertens (2002).

As estimativas dos teores de fibra em detergente neutro potencialmente digestível (FDNpD) e matéria seca potencialmente digestível (MSpD) dos alimentos foram obtidas de acordo com Paulino et al. (2006).

Tabela 2 - Composição química do concentrado e da cana-de-açúcar e pH da cana-de-açúcar in natura ou hidrolisada com óxido de cálcio

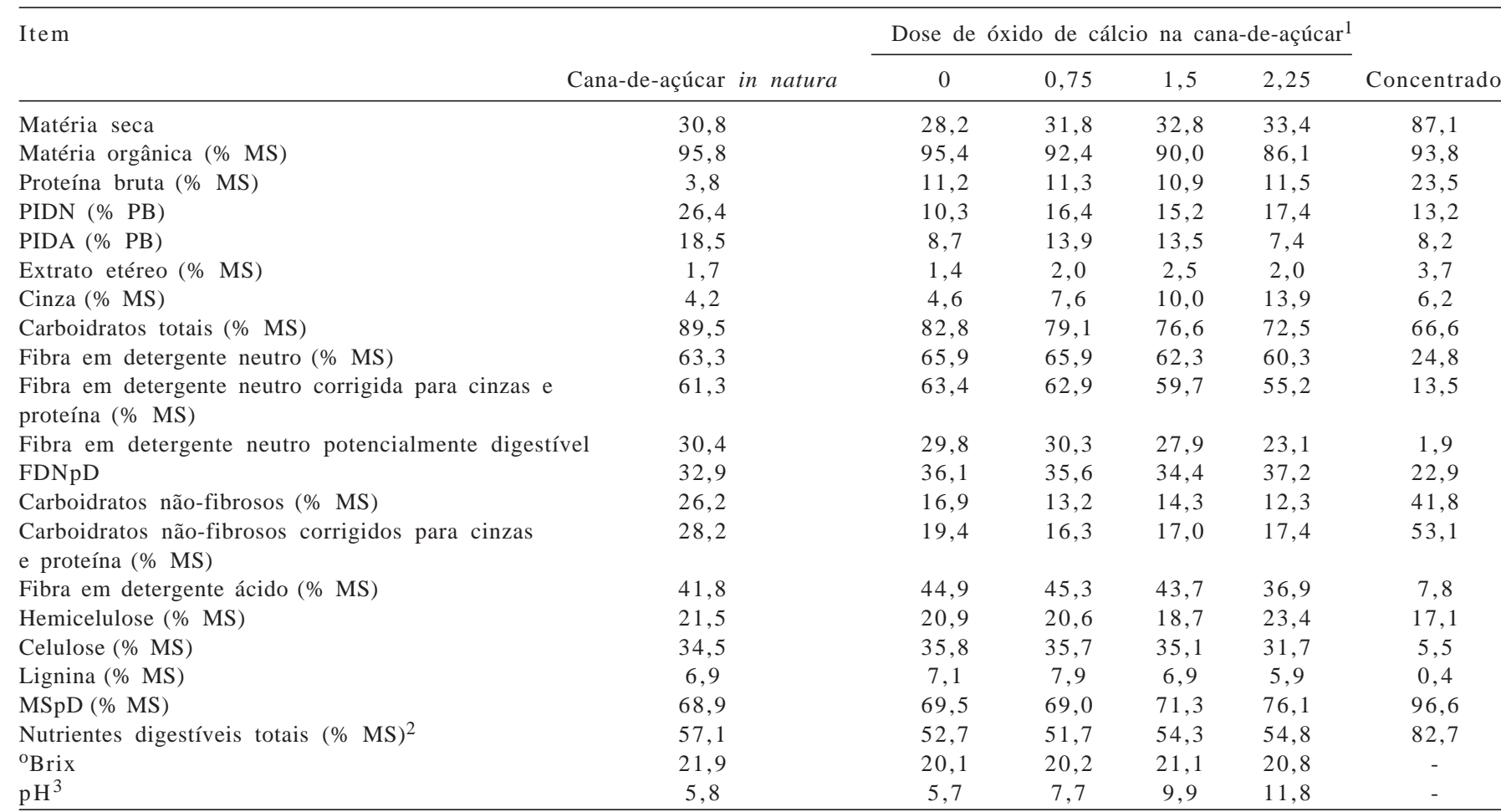

PIDN = proteína insolúvel em detergente neutro; PIDA = proteína insolúvel em detergente ácido; FDN pD = fibra em detergente neutro potencialmente digestível; MSpD = matéria seca potencialmente digestível.

${ }^{1}$ Cana-de-açúcar adicionada da mistura ureia + sulfato de amônia (9:1), na proporção de 1\% da matéria natural, e de óxido de cálcio aplicadas em \% da matéria natural.

2 Estimado segundo NRC (2001).

${ }^{3}$ Obtido na cana-de-açúcar antes da adição de $1 \%$ da mistura ureia + sulfato de amônia (9:1). 
Tabela 3 - Composição química das dietas experimentais

\begin{tabular}{|c|c|c|c|c|}
\hline Item & \multicolumn{4}{|c|}{ Óxido de cálcio na cana-de-açúcar ${ }^{1}$} \\
\hline Matéria seca & 45,3 & 47,9 & 48,5 & 49,0 \\
\hline Proteína bruta (\% MS) & 14,6 & 14,7 & 14,4 & 14,8 \\
\hline Proteína insolúvel em detergente neutro ${ }^{3}$ & 17,8 & 22,1 & 21,3 & 22,9 \\
\hline Proteína insolúvel em detergente ácido ${ }^{3}$ & 8,6 & 12,2 & 11,9 & 7,6 \\
\hline Carboidratos totais (\% MS) & 74,6 & 74,1 & 73,6 & 71,9 \\
\hline Fibra em detergente neutro (\% MS) & 54,0 & 54,0 & 51,5 & 50,0 \\
\hline Fibra em detergente neutro corrigida para cinzas e proteína (\% MS) & 48,9 & 48,6 & 46,3 & 43,1 \\
\hline Fibra em detergente neutro indigestíveis (\% MS) & 21,7 & 22,1 & 20,4 & 17,0 \\
\hline Fibra em detergente neutro potencialmente digestível (\% MS) & 32,3 & 31,9 & 31,1 & 33,0 \\
\hline Carboidratos não-fibrosos (\% MS) & 25,7 & 25,5 & 27,3 & 28,8 \\
\hline Lignina (\% MS) & 5,2 & 5,7 & 5,0 & 4,3 \\
\hline Matéria seca potencialmente digestível (\% MS) & 77,4 & 77,0 & 78,6 & 82,1 \\
\hline Nutrientes digestíveis totais $(\% \mathrm{MS})^{2}$ & 61,4 & 60,7 & 62,5 & 62,9 \\
\hline
\end{tabular}

${ }^{1}$ Cana-de-açúcar adicionada de ureia + sulfato de amônia (9:1), na proporção de 1\% da matéria natural, e de óxido de cálcio (\% da matéria natural).

2 Estimado segundo NRC (2001).

Os carboidratos totais (CT) foram estimados segundo Sniffen et al. (1992), como:

$$
\mathrm{CT}=100-(\% \mathrm{~PB}+\% \mathrm{EE}+\% \text { cinzas }) \text {. }
$$

Os teores de carboidratos não-fibrosos corrigidos para cinzas e proteína (CNFcp) foram calculados como proposto por Hall (2003), em que:

CNFcp $=(100-\%$ FDNcp $-\% \mathrm{~PB}-\% \mathrm{EE}-\%$ cinzas $)$.

Os nutrientes digestíveis totais (NDT) foram calculados segundo Weiss (1999), porém utilizando a FDN e CNF corrigindo para cinza e proteína, pela seguinte equação:

NDT $(\%)=$ PBD + FDNcpD + CNFcpD + 2,25EED . em que: $\mathrm{PBD}=\mathrm{PB}$ digestível; FDNcpD = FDNcp digestível; $\mathrm{CNF} c \mathrm{D}=\mathrm{CNF}$ cp digestíveis; $\mathrm{e} \mathrm{EED}=\mathrm{EE}$ digestível.

Os teores de nutrientes digestíveis totais estimados (NDTest) dos alimentos e dietas totais, foram calculados conforme equações descritas pelo NRC (2001).

Foi estimado o consumo de MS, MO, PB, EE, FDN, FDNcp, FDNi, carboidratos totais, carboidratos não fibrosos corrigido para cinza e proteína e nutrientes digestíveis totais em kg/dia, de MS, MO, FDN, FDNcp e NDT (em \%PV) e MS em relação ao peso metabólico ( $\left.\mathrm{g} / \mathrm{kg}^{0,75}\right)$.

O consumo de MS, os consumos de PB, EE, FDN e CNF digestíveis e o consumo NDT observados no experimento foram comparados com os valores estimados pelo NRC (2001).

O procedimento de validação foi realizado de forma independente aos efeitos de óxido de cálcio, por intermédio do ajustamento de modelo de regressão linear simples dos valores preditos e observados, testando-se as estimativas dos parâmetros de regressão sob as seguintes hipóteses:

$$
\begin{array}{ll}
H_{0}: \beta_{0}=0 & H_{0}: \beta_{1}=1 \\
H_{a}: \beta_{0} \neq 0 & H_{a}: \beta_{1} \neq 0
\end{array}
$$

Em caso de não-rejeição de ambas as hipóteses de nulidade, optou-se pela similaridade entre valores preditos e observados. Em situação contrária, estimou-se o vício global das estimativas segundo Detmann et al. (2005) assumindo intercepto nulo, como:

$$
\mathrm{B}(\%)=(\hat{\beta}-1) \times 100
$$

em que: $\mathrm{B}=$ vício global das estimativas (\%); $\hat{\beta}$ estimativa do coeficiente de inclinação para a relação entre consumo observado e predito assumindo-se intercepto nulo.

Para estimar a digestibilidade aparente dos nutrientes, foi efetuada coleta de fezes dos animais durante dois dias alternados, em horários diferentes (às $12 \mathrm{~h}$ e às $17 \mathrm{~h}$ ), entre o $20^{\circ}$ e $21^{\circ}$ dias do experimento. As amostras de fezes foram pré-secas, trituradas em moinho de faca com peneira de malha de 1,0 mm, compostas por animal e posteriormente armazenadas para as análises. Para a estimativa da excreção fecal, foi utilizada a fibra em detergente neutro indigestível (FDNi) como indicador interno (Detmann et al., 2001; Detmann et al., 2007). Amostras dos alimentos fornecidos (cana, concentrado), sobras e fezes foram incubadas por 240 horas (Casali et al., 2008) em duplicata (20 mg MS/cm²) em sacos de tecido não-tecido (TNT $100 \mathrm{~g} / \mathrm{m}^{2}$ ) no rúmen de um novilho mestiço Holandês- 
zebu recebendo dieta mista. Após este período o material remanescente da incubação foi submetido à extração com detergente neutro (Mertens, 2002) para quantificação dos teores de FDNi. Os valores de excreção fecal foram obtidos por intermédio da relação entre consumo e concentração fecal de FDNi.

As estimativas de consumo, coeficientes de digestibilidades e NDT foram comparadas entre as dietas por intermédio da decomposição da soma de quadrados relacionada às doses de óxido de cálcio na cana-de-açúcar, por meio de contrastes ortogonais (Tabela 4).

Ao primeiro contraste (A) atribuiu-se a comparação entre as médias da dieta controle (cana in natura) e dietas envolvendo cana-de-açúcar com óxido de cálcio. Os contrastes representados pelas letras B e C permitiram a

Tabela 4 - Distribuição dos coeficientes para os contrastes ortogonais empregados na decomposição da soma de quadrados

\begin{tabular}{ccccc}
\hline \multirow{4}{*}{ Contraste } & \multicolumn{4}{c}{ Doses de óxido de cálcio na cana-de-açúcar } \\
\cline { 2 - 5 } & Cana in natura & 0,75 & 1,5 & 2,25 \\
\hline \multicolumn{5}{c}{ Coeficientes } \\
A & +3 & -1 & -1 & -1 \\
B & 0 & -1 & 0 & +1 \\
C & 0 & -1 & +2 & -1 \\
\hline
\end{tabular}

avaliação de efeitos de ordem linear e quadrática em função das doses de óxido de cálcio na cana-de-açúcar, respectivamente. Os procedimentos estatísticos foram realizados com o auxílio do programa SAS (Statistical Analisys System), adotando-se 0,05 como nível crítico de probabilidade.

\section{Resultados e Discussão}

Os consumos de PB (kg/dia) e NDT (\%PV) das dietas com cana-de-açúcar hidrolisada foram superiores aos da cana in natura. Observou-se efeito linear associado negativamente aos consumos de $\mathrm{MO}(\mathrm{P}<0,05)$, $\mathrm{FDN}(\mathrm{P}<0,05)$, FDNcp $(\mathrm{P}<0,01)$ e NDT $(\mathrm{P}<0,01)$, em \%PV. Nenhum efeito significativo quadrático $(\mathrm{P}>0,05)$ foi verificado para as variáveis relacionadas ao consumo (Tabela 5). Não houve relação entre consumo de MS, expresso em $\mathrm{g} / \mathrm{kg}^{0,75}$, e as doses de óxido de cálcio aplicadas à cana-de-açúcar.

Os resultados observados para o consumo de nutrientes contrariam a premissa de que a adição de produtos alcalinos em volumosos altera a estrutura química e, consequentemente, aumenta o consumo voluntário e a digestibilidade dos nutrientes. O uso de produtos alcalinos, como o óxido de cálcio, justifica-se pelo fato de que a lignina de gramíneas é particularmente susceptível à ação hidrolítica desses produtos, rompendo ligações covalentes do tipo éster entre

Tabela 5 - Consumos de nutrientes em novilhas alimentadas com dietas contendo cana-de-açúcar tratada ou não com óxido de cálcio

\begin{tabular}{|c|c|c|c|c|c|c|c|c|}
\hline \multirow[t]{2}{*}{ Item } & \multicolumn{4}{|c|}{ Dose de óxido de cálcio (\%) } & \multirow[b]{2}{*}{ CV (\%) } & \multicolumn{3}{|c|}{ Valor-P } \\
\hline & $\begin{array}{l}\text { Cana in } \\
\text { natura }\end{array}$ & 0,75 & 1,5 & 2,25 & & $\begin{array}{l}\text { Cana vs. óxido } \\
\text { de cálcio }\end{array}$ & Linear & Quadrático \\
\hline \multicolumn{9}{|c|}{ Consumo (kg/dia) } \\
\hline Matéria seca & 5,16 & 5,05 & 4,96 & 4,60 & 26,3 & 0,6788 & 0,5877 & 0,8520 \\
\hline Matéria orgânica & 4,90 & 4,70 & 4,53 & 4,06 & 26,2 & 0,4545 & 0,4064 & 0,8203 \\
\hline Proteína bruta & 0,95 & 0,82 & 0,69 & 0,61 & 27,8 & 0,0421 & 0,1409 & 0,8595 \\
\hline Extrato etéreo & 0,11 & 0,13 & 0,14 & 0,11 & 26,4 & 0,2657 & 0,4829 & 0,2697 \\
\hline Fibra em detergente neutro & 2,70 & 2,67 & 2,58 & 2,31 & 26,0 & 0,6192 & 0,4081 & 0,8197 \\
\hline $\begin{array}{l}\text { Fibra em detergente neutro corrigida para } \\
\text { cinzas e proteína }\end{array}$ & 2,45 & 2,41 & 2,35 & 2,00 & 26,6 & 0,5370 & 0,3001 & 0,6752 \\
\hline Fibra em detergente neutro indigestível & 1,08 & 1,09 & 1,04 & 0,80 & 26,7 & 0,4813 & 0,0979 & 0,5386 \\
\hline Carboidratos totais & 3,84 & 3,75 & 3,69 & 3,33 & 25,9 & 0,6202 & 0,4956 & 0,7730 \\
\hline $\begin{array}{l}\text { Carboidratos não-fibrosos corrigidos para } \\
\text { cinzas e proteína }\end{array}$ & 1,39 & 1,34 & 1,35 & 1,34 & 25,2 & 0,7913 & 0,9905 & 0,9625 \\
\hline Nutrientes digestíveis totais & 4,12 & 3,97 & 3,45 & 3,08 & 25,6 & 0,2184 & 0,1531 & 0,8779 \\
\hline \multicolumn{9}{|c|}{ Consumo (\% do peso vivo) } \\
\hline Matéria seca & 2,31 & 2,29 & 2,30 & 2,10 & 9,2 & 0,4826 & 0,1609 & 0,3897 \\
\hline Matéria orgânica ${ }^{1}$ & 2,19 & 2,13 & 2,10 & 1,85 & 9,0 & 0,1053 & 0,0331 & 0,3264 \\
\hline Fibra em detergente neutro ${ }^{2}$ & 1,21 & 1,21 & 1,19 & 1,06 & 8,9 & 0,3211 & 0,0379 & 0,3210 \\
\hline $\begin{array}{l}\text { Fibra em detergente neutro corrigida para } \\
\text { cinza e proteína }{ }^{3}\end{array}$ & 1,10 & 1,09 & 1,08 & 0,92 & 8,8 & 0,1778 & 0,0090 & 0,1217 \\
\hline Nutrientes digestíveis totais ${ }^{4}$ & 1,41 & 1,39 & 1,29 & 1,16 & 7,4 & 0,0227 & 0,0014 & 0,7124 \\
\hline \multicolumn{9}{|c|}{ Consumo $\left(\mathrm{g} / \mathrm{kg}^{0,75}\right)$} \\
\hline Matéria seca & 88,88 & 87,77 & 87,73 & 80,6 & 11,6 & 0,5052 & 0,2732 & 0,5263 \\
\hline
\end{tabular}

${ }^{1} \hat{Y}=2,30186-0,183462 X\left(r^{2}=0,8414\right) .{ }^{2} \hat{Y}=1,30198-0,0996947 X\left(r^{2}=0,8350\right) .{ }^{3} \hat{Y}=1,20327-0,115445 X\left(r^{2}=0,7705\right) .{ }^{4} \hat{Y}=1,51647-0,15700 X\left(r^{2}=0,9903\right)$. 
a lignina e a parede celular (Van Soest, 1994). Esses benefícios estão associados ao aumento do consumo e da digestibilidade como verificado por Ezequiel et al. (2005) com cana-de-açúcar tratada com $\mathrm{NaOH}$.

Ausência de efeito e/ou efeitos negativos à ação química da cana-de-açúcar com óxido de cálcio sobre o consumo voluntário de alimentos foram reportados por outros autores na literatura (Moraes et al., 2008; Campos, 2007; Pontes, 2007).

Avaliando a adição de $1 \%$ de cálcio no tratamento da cana-de-açúcar por 24 horas de armazenamento, Moraes et al. (2008) observaram redução no consumo voluntário de novilhas mestiças, os quais obtiveram melhores resultados com a cana in natura cortada e fornecida no mesmo dia, sem adição do óxido de cálcio. A ausência de resposta positiva do óxido de cálcio na cana-de-açúcar sobre o consumo voluntário de nutrientes, segundo os autores, proporcionou menores ganhos de peso em relação aos animais que foram alimentados com cana-de-açúcar in natura $(0 \% \mathrm{CaO})$. O consumo de $\mathrm{MS}$ e os ganhos médios diários registrados pelos autores foram, respectivamente, de $3,44 \mathrm{~kg} /$ dia e 308,1 g/dia na dieta com $1 \%$ de óxido de cálcio e 4,18 kg/dia e 439,0 g/dia, na dieta sem a adição de óxido de cálcio. A cana-de-açúcar não afetou o consumo de MS, cujos valores foram de 5,16; 5,05; 4,96 e 4,60 kg/dia, respectivamente, para as doses $0 ; 0,75 ; 1,5$ e $2,25 \%$ de óxido de cálcio.

A redução no consumo de fibra, em \% do peso vivo, verificada para a adição do óxido de cálcio na cana-deaçúcar, está de acordo com os resultados descritos por Campos (2007), que, do mesmo modo, observou redução desta variável ao avaliar a adição de $0,6 \%$ desse aditivo na cana-de-açúcar em combinação com o fornecimento de diferentes níveis de uréia (0; 0,33; 0,66 e 0,99\%, com base na $\mathrm{MN}$ ) em dietas para ovinos.
Resultados positivos quanto à utilização de aditivos químicos têm sido apresentados em trabalhos com uso de amônia anidra $\left(\mathrm{NH}_{3}\right)$ e uréia (Pires et al., 2003; Cardoso et al., 2004; Pires et al., 2004). De acordo com Pires et al. (2004), um dos efeitos da ação da amônia sobre a forragem é a desestruturação no complexo formado pelos componentes da fibra (celulose, hemicelulose e lignina), oferecendo aos microrganismos ruminais maior área de exposição e, consequentemente, aumentando o grau de utilização das diferentes frações da fibra. Em estudo conduzido por Cardoso et al. (2004) os autores observaram maiores consumos de MS e FDN em bovinos alimentados com palhada de arroz tratada com $3 \%$ de $\mathrm{NH}_{3}$ que, de acordo com os resultados relatados pelos autores, equiparou-se à silagem de sorgo, sendo estes dois maiores que os obtidos para palhada não-amonizada e a cana-de-açúcar.

Outro resultado positivo do uso de aditivo químico foi evidenciado por Pires et al. (2004), que avaliaram o bagaço de cana-de-açúcar sem aditivo e o bagaço de cana-de-açúcar tratado com 2,5\% de sulfeto de sódio $\left(\mathrm{Na}_{2} \mathrm{~S}\right), 4 \%$ de $\mathrm{NH}_{3}$ ou com 2,5\% de $\mathrm{Na}_{2} \mathrm{~S}$ combinado com $4 \%$ de $\mathrm{NH}_{3}$ e relataram que, independentemente da fonte de $\mathrm{Na}_{2} \mathrm{~S}$ aplicada, a adição de $4 \%$ de $\mathrm{NH}_{3}$ ao bagaço de cana aumentou o consumo voluntário e o ganho de peso de novilhas mestiças. De acordo com Garcia \& Neiva (1994), além do efeito sobre os componentes da parede celular, o incremento de compostos nitrogenados em volumosos tratados com ureia ou $\mathrm{NH}_{3}$ são importantes para o desenvolvimento dos microrganismos ruminais e a eficiência dos mesmos sobre o material.

Os coeficientes de digestibilidade da MO, FDN, FDNcp, CT e CNFcp e os teores de NDT das dietas não foram influenciados $(\mathrm{P}>0,05)$ pelas doses de óxido de cálcio na cana-de-açúcar (Tabela 6), verificando ausência de efeito significativo $(\mathrm{P}>0,05)$ em todos os contrastes testados. Verificou-se, entretanto, que os coeficientes de

Tabela 6 - Coeficientes de digestibilidade e nível de nutrientes digestíveis totais em novilhas alimentadas com dietas contendo cana-deaçúcar tratada com óxido de cálcio

\begin{tabular}{|c|c|c|c|c|c|c|c|c|c|}
\hline \multirow[t]{2}{*}{ Item } & \multicolumn{4}{|c|}{ Dose de óxido de cálcio (\%) } & \multirow[b]{2}{*}{ CV (\%) } & \multicolumn{4}{|c|}{ Valor-P } \\
\hline & Cana in natura & 0,75 & 1,5 & 2,25 & & Cana & vs. óxido de cálcio & Linear & Quadrático \\
\hline Matéria seca & 60,5 & 60,3 & 54,9 & 54,9 & 6,2 & & 0,0544 & 0,0289 & 0,1880 \\
\hline Matéria orgânica & 62,4 & 62,7 & 58,7 & 59,4 & 5,5 & & 0,2346 & 0,1452 & 0,2243 \\
\hline Proteína bruta & 75,9 & 75,5 & 68,7 & 64,2 & 4,9 & & 0,0026 & 0,0001 & 0,6180 \\
\hline Extrato etéreo ${ }^{1}$ & 74,1 & 81,1 & 83,3 & 86,4 & 5,4 & & 0,0007 & 0,0798 & 0,8445 \\
\hline Fibra em detergente neutro ${ }^{2}$ & 44,3 & 44,1 & 37,7 & 38,1 & 11,8 & & 0,1005 & 0,0666 & 0,2216 \\
\hline FDNcp & 44,2 & 43,5 & 40,2 & 39,2 & 12,7 & & 0,2482 & 0,2109 & 0,7041 \\
\hline Carboidratos totais & 58,6 & 59,3 & 55,9 & 57,6 & 6,3 & & 0,6119 & 0,4682 & 0,2130 \\
\hline CNFcP & 83,8 & 87,3 & 83,2 & 85,5 & 4,5 & & 0,4362 & 0,4464 & 0,1370 \\
\hline Nutrientes digestíveis totais & 55,4 & 56,3 & 54,0 & 53,0 & 6,0 & & 0,5756 & 0,1332 & 0,7400 \\
\hline
\end{tabular}

$1 \hat{Y}=62,1018-3,58335 X\left(r^{2}=0,7527\right) .{ }^{2} \hat{Y}=80,7663-7,49334 X\left(r^{2}=0,9897\right)$.

FDNcp - fibra em detergente neutro corrigida para cinzas e proteína; CNFcp - carboidratos não-fibrosos corrigidos para cinzas e proteína. 
digestibilidade da MS e PB se associaram de forma linear e negativamente $(\mathrm{P}<0,05)$ às doses de óxido de cálcio aplicadas à cana-de-açúcar.

Essas respostas observadas para as digestibilidades dos nutrientes não condizem com os resultados esperados para volumosos tratados com produtos alcalinos. A principal justificativa em se usar produtos alcalinos como o óxido de cálcio e amônia anidra diz respeito às alterações potenciais sobre a parede celular e consequente aumento na digestibilidade da MS e FDN, o que não foi verificado neste estudo. Pelo que tudo indica, o óxido de cálcio prejudicou a eficiência de utilização do nitrogênio, pois foi utilizado 1\% de uréia na cana-de-açúcar e o concentrado na proporção de $29 \%$ em todas as dietas, esperando-se, assim, no mínimo que a digestibilidade da PB fosse similar entre as dietas, mas isso não ocorreu. A redução no coeficiente digestibilidade da PB, assim como nos coeficientes de digestibilidade da MS, podem ser atribuídos aos elevados valores de $\mathrm{pH}$ na cana-de-açúcar tratada com óxido de cálcio, que podem ter sido a causa de menores consumos de alguns nutrientes.

Por outro lado, experimentos avaliando a digestibilidade in vitro da MS da cana-de-açúcar tratada com óxido de cálcio tem mostrado resultados amplamente promissores (Cavali et al., 2010; Balieiro Neto et al., 2007). Cavali et al. (2010) estudaram a adição de doses de 0; 0,5; 1,0; 1,5 e 2,0\% de óxido de cálcio no momento da ensilagem de cana-de-açúcar e verificaram aumento na digestibilidade in vitro da MS, relatando valores de 48,4; 65,6; 74,9; 78,2 e $81,5 \%$, respectivamente. Estudo com resultados positivos obtidos in vitro também foram relatados para a palha de trigo aditivada com hidróxido de cálcio $\left[\mathrm{Ca}(\mathrm{HO})_{2}\right]$, dentre eles o de Haddad et al. (1998), que observaram valores de digestibilidade in vitro da FDN de 41,9; 56,5; 57,$7 ; 56,9 ; 69,7$ e $64,1 \%$, respectivamente, para as doses de 0, 1, 2, 3, 4 e $5 \%$ de $\mathrm{Ca}(\mathrm{OH})_{2}$. Constitui-se fato notório em estudos in vitro a obtenção de bons resultados para as digestibilidades de MS e FDN em volumosos tratados com $\mathrm{CaO}$ ou $\mathrm{Ca}(\mathrm{OH})_{2}$, contudo, na prática os resultados obtidos in vivo tem mostrado que nem sempre isso acontece.

Avaliando a eficiência do tratamento alcalino da canade-açúcar com óxido de cálcio, Moraes et al. (2008) forneceram a novilhas mestiças dietas contendo cana-deaçúcar in natura ou tratada com $1 \%$ de óxido de cálcio por 24 horas e três ofertas de concentrado em percentagem do peso vivo (0; 0,5 e $1 \%)$. O autor observou que independentemente da oferta de concentrado, a cana-deaçúcar tratada com $1 \%$ de óxido de cálcio provocou redução nos coeficientes de digestibilidade aparente total da MS, MO, PB e CT e não exerceu nenhum efeito sobre os coeficientes de digestibilidade aparente total de EE e FDN. Já para a digestibilidade aparente ruminal, nenhum efeito do tratamento químico foi observado sobre os coeficientes de digestibilidade dos nutrientes. Os resultados observados no presente estudo, no qual se verificou ausência de efeito positivo do tratamento químico com óxido de cálcio na melhoria da digestibilidade aparente total dos nutrientes das dietas com cana-de-açúcar, estão de acordo com os relatados pelo autor.

Outros trabalhos avaliando a cana-de-açúcar tratada com óxido de cálcio são relatados na literatura. No estudo conduzido por Pontes (2007), a autora também encontrou resultados negativos para o tratamento químico da canade-açúcar com óxido de cálcio sobre os coeficientes de digestibilidade dos nutrientes. Nesse trabalho conduzido pelo autor foram testados a cana-de-açúcar tratada em dois tempos de armazenamentos ( 0 e 24 horas) com três doses (0; 0,5 e 1\%) de óxido de cálcio (\% MN) em dietas para ovinos, sendo obtida redução na digestibilidade da MS e ausência de efeito na digestibilidade dos demais nutrientes. Os baixos consumos e coeficientes de digestibilidade observados nos trabalhos de pesquisa, decorrentes da baixa eficiência do $\mathrm{CaO}$ na cana-de-açúcar, ainda não são bem compreendidos, porém, pelo que tudo indica, as reduções observadas tem uma forte relação com a elevação do $\mathrm{pH}$ ruminal, o qual pode ter provocado redução na eficiência microbiana de degradação e utilização dos alimentos. Essas pressuposições podem ser suportadas pelos relatos de Detmann et al. (2008) evidenciando que a digestibilidade não é função apenas do alimento, pois na grande maioria dos casos ela depende dos nutrientes disponíveis a partir de outros alimentos. No presente trabalho, o único item que se diferenciou entre as dietas foram as doses de óxido de cálcio aplicadas à cana-deaçúcar, sendo adicionado 1\% de uréia na cana-de-açúcar em todos as dietas e o concentrado a base de milho e farelo de soja foi o mesmo em todas as dietas. Desse modo, acredita-se que o óxido de cálcio tenha modificado o meio, aumentado o pH e provocando a redução no consumo e digestibilidade dos nutrientes. Registraram-se durante a condução do experimento valores de $\mathrm{pH}$ na cana-de-açúcar de 5,$7 ; 7,7 ; 9,9$ e 11,8, respectivamente, para as doses de 0; 0,75; 1,5 e 2,25\% de óxido de cálcio na cana-de-açúcar.

A temperatura da cana-de-açúcar no momento do oferecimento das dietas aos animais também tem sido relatada como um possível fator que contribuir para os baixos consumos da cana-de-açúcar tratada com óxido de cálcio (Moraes et al., 2008; Pontes, 2007). No presente trabalho, para as doses 1,5 e 2,25\% verificou-se elevação máxima da temperatura do material de $38^{\circ} \mathrm{C}$ após as seis 
horas iniciais de tratamento, diminuindo após este período, e chegando a patamares de $32^{\circ} \mathrm{C}$ após as 24 horas. Por outro lado, na cana com adição de $0,75 \%$ de óxido de cálcio, observou-se elevação gradativa da temperatura até atingir, o valor máximo de $37,6^{\circ} \mathrm{C}$ registrado com 24 horas de tratamento, no momento do fornecimento aos animais. A temperatura na cana com esta dose de óxido de cálcio comportou-se de forma diferente devido à provável fermentação, uma vez que a dose $0,75 \%$ não é suficiente para inibir o processo fermentativo da cana-de-açúcar. Apesar dessas variações obtidas nas temperaturas da cana-de-açúcar tratada com doses de óxido de cálcio, acredita-se que esta variação não teve influência sobre o consumo e digestibilidade dos nutrientes, uma vez que a temperatura da cana-de-açúcar não ultrapassou em momento algum os valores relatados para o ambiente ruminal $39-42^{\circ} \mathrm{C}$ (Kozloski, 2002). Além disso, quando o concentrado era misturado à cana-de-açúcar no momento do oferecimento das dietas, pressupõe-se diminuição dos valores relatados anteriormente.

A avaliação estatística do coeficiente de inclinação da reta para o consumo de MS apontou não-aceitação da hipótese de nulidade $(\mathrm{P}<0,01)$ (Tabela 7$)$. O mesmo foi observado para o intercepto, cuja análise estatística também indicou não-aceitação da hipótese de nulidade, apontando, portanto, na relação analisada, a existência de um valor constante (vício) subtraído aos valores estimados de forma independente aos valores observados. Submetendo-se esta variável ao ajuste de equação de regressão sem considerar o intercepto, observou-se subestimação do consumo de MS estimado pelo NRC (2001) em relação ao observado, apresentando vício global de -7,3\% (Tabela 8).

Os resultados obtidos para o consumo de MS (Figura 2) estão em concordância com os obtidos por Oliveira (2005), que relatou presença de vício global de -5,9\% para a relação entre consumo estimado pelo NRC (2001) e o observado. Ao avaliar a relação entre o consumo de MS estimado pelos sistemas NRC (1989), CNCPS 5.0 e AFRC (1993) com os obtidos no experimento, o autor observou também subestimação dos consumos, com presença de maiores vícios globais -17,6; -17,1 e -11,9\%, respectivamente.

No tocante aos consumos de PB, EE, FDN e CNF digestíveis e NDT, a análise estatística apontou nãoaceitação da hipótese de nulidade para o intercepto sobre os consumos de PB e FDN digestível $(\mathrm{P}<0,01)$ e NDT $(\mathrm{P}<0,04)$ (Tabela 7). Por outro lado, na avaliação estatística dos coeficientes de inclinação das retas para os consumos

Tabela 8 - Estimativas de vícios globais obtidos para consumo de matéria seca e das frações digestíveis

\begin{tabular}{lc}
\hline Item & Vício global ${ }^{1}$ \\
\hline Matéria seca & $-7,3 \%$ \\
Proteína bruta digestível & $-22,7 \%$ \\
Carboidratos não-fibrosos digestíveis & $-26,8 \%$ \\
Nutrientes digestíveis totais & $-20,9 \%$ \\
\hline
\end{tabular}

${ }^{1}$ Como houve rejeição da hipótese associada ao coeficiente de inclinação para os consumos de MS, PB digestível, CNF e NDT (Tabela 7), o vício global foi estimado como proposto por Detmman et al. (2005): $\mathrm{B}(\%)=(\beta-1) \times 100$

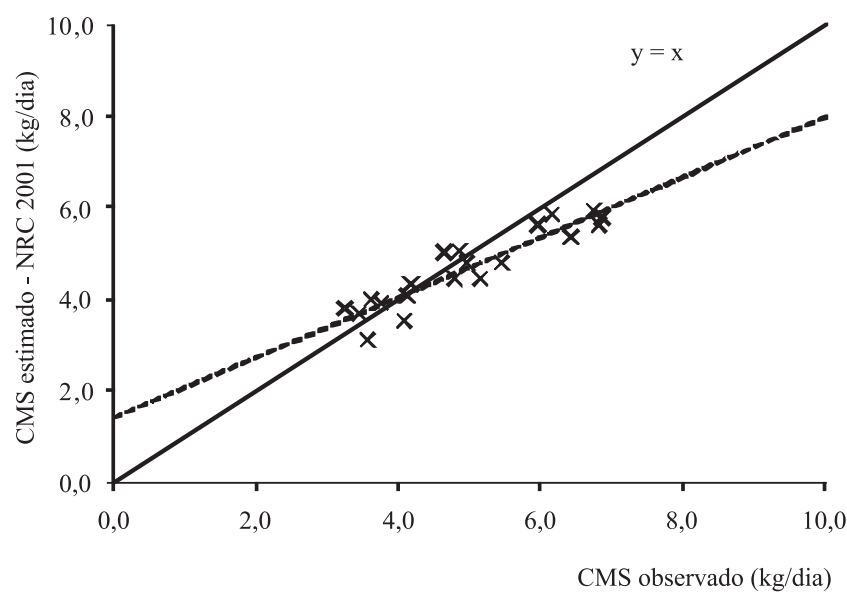

Figura 2 - Relação entre consumo de matéria seca (CMS) observado e estimado pelo NRC (2001) em novilhas (a linha tracejada corresponde à reta de mínimos quadrados).

Tabela 7 - Estimativas de parâmetros de regressão e níveis descritivos de probabilidade (Valor-P) associados às hipóteses de nulidade para as relações entre consumo observado e estimado pelo NRC (2001) em novilhas

\begin{tabular}{|c|c|c|c|c|c|c|c|}
\hline \multirow{3}{*}{ Item } & \multirow{2}{*}{\multicolumn{2}{|c|}{ Médias (kg/dia) }} & \multirow[b]{3}{*}{ CV (\%) } & \multicolumn{4}{|c|}{ Regressão linear } \\
\hline & & & & \multicolumn{2}{|c|}{ Intercepto } & \multicolumn{2}{|c|}{ Coeficiente de inclinação } \\
\hline & Observado & Estimado & & Estimativa & Valor-Pa & Estimativa & Valor-P ${ }^{b}$ \\
\hline Matéria seca & 4,943 & 4,661 & 7,2 & 1,4329 & 0,0003 & 0,6531 & $\mathrm{P}<0,0001$ \\
\hline Proteína bruta digestível & 0,554 & 0,446 & 18,2 & 0,1743 & 0,0065 & 0,4908 & $\mathrm{P}<0,0001$ \\
\hline Extrato etéreo digestível & 0,100 & 0,097 & 15,9 & 0,0086 & 0,5381 & 0,8897 & 0,4174 \\
\hline Fibra em detergente neutro digestível & 0,959 & 1,275 & 9,8 & 0,4424 & 0,0007 & 0,8677 & 0,2410 \\
\hline Carboidratos não-fibrosos digestíveis & 1,146 & 0,840 & 20,6 & 0,0309 & 0,8619 & 0,7062 & 0,0642 \\
\hline Nutrientes digestíveis totais & 2,884 & 2,319 & 12,9 & 0,6737 & 0,0307 & 0,5751 & 0,0003 \\
\hline
\end{tabular}

${ }^{\mathrm{a}} \mathrm{H}_{0}: \beta_{0}=0 ; \mathrm{H}_{\mathrm{a}}: \beta_{0}{ }^{1} 0{ }^{\mathrm{b}} \mathrm{H}_{0}: \beta_{1}=1 ; \mathrm{H}_{\mathrm{a}}: \beta_{1}{ }^{1} 1$. 
dos nutrientes digestíveis e do NDT, verificou-se nãoaceitação da hipótese de nulidade para os consumos de $\mathrm{PB}$ $(\mathrm{P}<0,01)$ e CNF $(\mathrm{P}<0,07)$ digestíveis e para o consumo de NDT $(\mathrm{P}<0,01)$, enquanto, para o consumo de EE digestível, verificou-se aceitação de ambas as hipóteses de nulidades, denotando ausência de vício constante sobre essa variável (Figura 3), com distribuição dos pontos mais próxima da reta de equalidade $(\mathrm{x}=\mathrm{y})$ e $\mathrm{o}$ adequado ajuste da reta de mínimos quadrados.
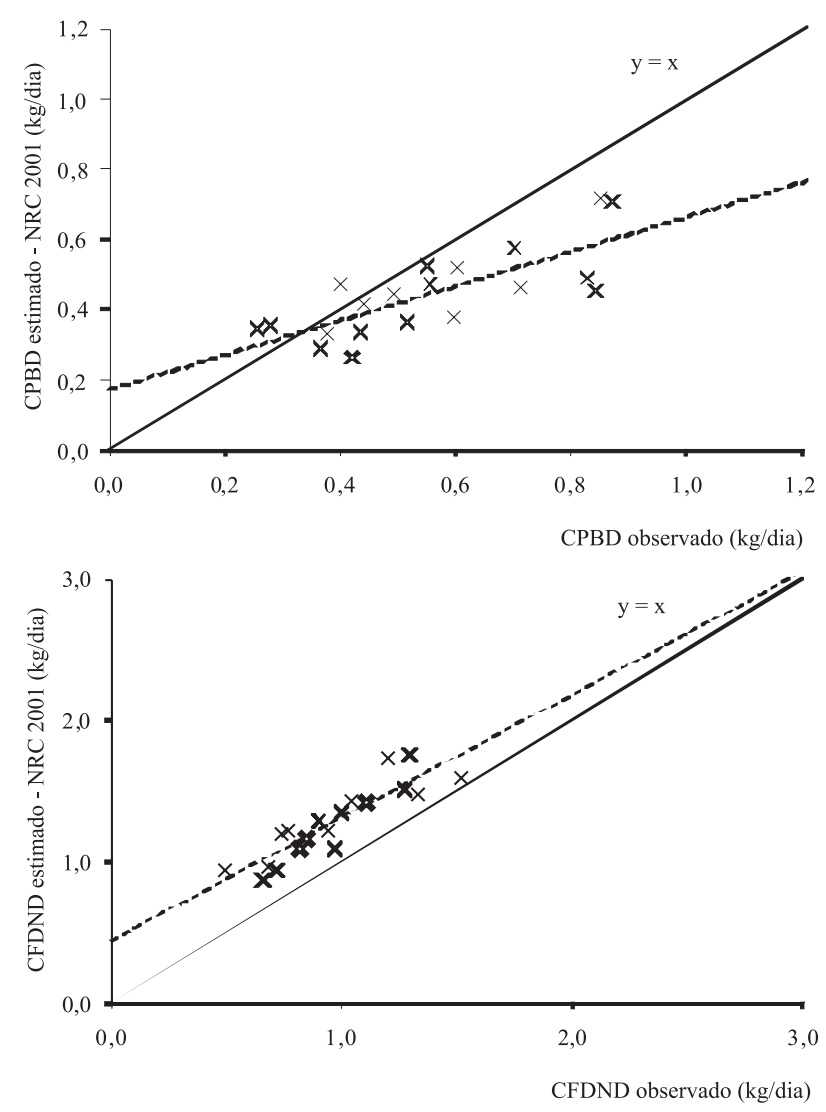

A ausência de efeito sobre a hipótese de nulidade para o coeficiente de inclinação da reta e a não-aceitação da hipótese de nulidade para o intercepto $(\mathrm{P}<0,01)$ para o consumo de FDN digestível (Tabela 7), apontou vício de 0,44 kg/dia para esta variável. Já para os consumos de PB e CNF digestíveis e NDT, os quais tiveram as hipóteses de nulidade associadas às estimativas dos coeficientes de inclinação rejeitadas, os vícios globais estimados foram $-22,7 ;-26,8$ e -20,9\%, respectivamente (Tabela 8). Esse
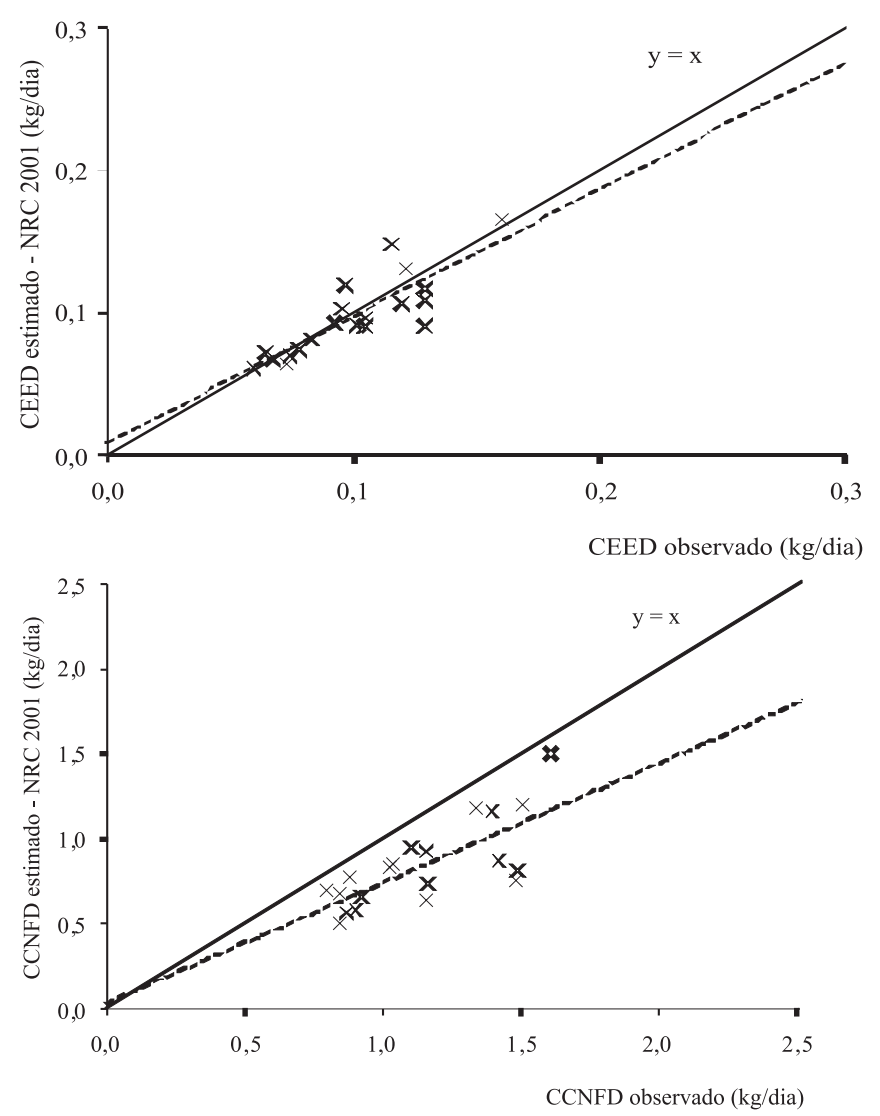

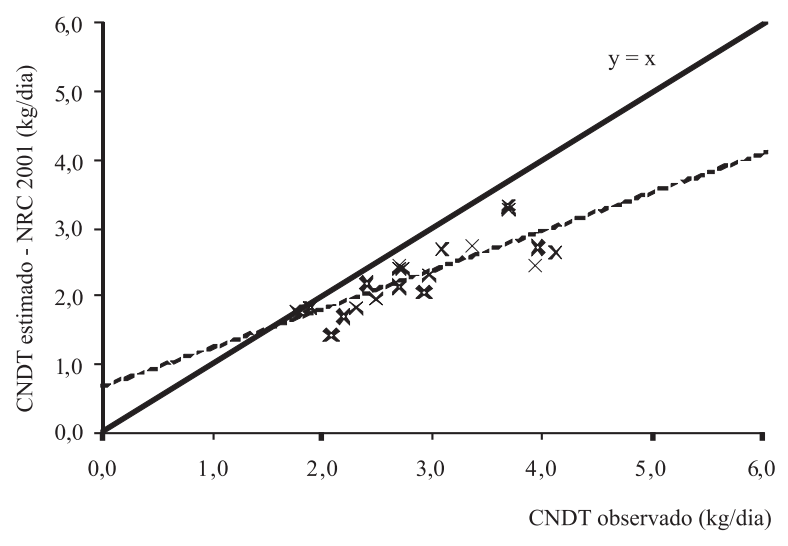

Figura 3 - Relação entre consumo de proteína bruta digestível (CPBD), extrato etéreo digestível (CEED), fibra em detergente neutro digestível (FDND), carboidratos não-fibrosos digestíveis (CNFD) e nutrientes digestíveis totais (CNDT) observado e estimado pelo NRC (2001) em novilhas (a linha tracejada corresponde à reta de mínimos quadrados). 
comportamento vicioso observado para estas variáveis (consumo de PB e CNF digestíveis e consumo de NDT) pode ser melhor visualizado pela elevada concentração de pontos abaixo da reta de equalidade $(\mathrm{x}=\mathrm{y})$, respectivamente, denotando subestimação dos consumos desses nutrientes (Figura 3).

\section{Conclusões}

A adição de óxido de cálcio na cana-de-açúcar em doses de até $2,25 \%$ não melhora o consumo nem a digestibilidade dos nutrientes em novilhas mestiças, portanto, não é recomendável. As equações propostas pelo National Research Council não são eficientes para estimar o consumo de matéria seca e o valor energético de dietas contendo cana-de-açúcar nas condições experimentais.

\section{Referências}

AGRICULTURAL AND FOOD RESEARCH COUNCIL - AFRC. Energy and protein requeriment of ruminant. Wallingford: CAB Internacional, 1993. 159p.

BALIEIRO NETO, G.; SIQUEIRA, G.R.; REIS, R.A. et al. Óxido de cálcio como aditivo na ensilagem de cana-de-açúcar. Revista Brasileira de Zootecnia, v.36, n.5, p.1231-1239, 2007.

CAMPOS, M.M. Valor nutritivo da cana-de-açúcar adicionada ou não com óxido de cálcio com diferentes níveis de uréia em ovinos. 2007. 67f. Dissertação (Mestrado em Ciência Animal) - Escola de Veterinária da Universidade Federal de Minas Gerais, Belo Horizonte.

CARDOSO, G.C.; GARCIA, R.; SOUZA, A.L. et al. Desempenho de novilhos Simental alimentados com silagem de sorgo, canade-açúcar e palhada de arroz tratada ou não com amônia anidra. Revista Brasileira de Zootecnia, v.33, n.6, p.2132-2139, 2004 (supl. 2).

CASALI, A.O.; DETMANN, E.; VALADARES FILHO, S.C. et al. Influência do tempo de incubação e do tamanho de partículas sobre os teores de compostos indigestíveis em alimentos e fezes bovinas obtidos por procedimentos in situ. Revista Brasileira de Zootecnia, v.37, n.2, p.335-342, 2008.

CAVALI, J.; PEREIRA, O.G.; VALADARES FILHO, S.C. et al. Bromatological and microbiological characteristics of sugarcane silages treated with calcium oxide. Revista Brasileira de Zootecnia, v.39, n.7, p.1398-1408, 2010.

CNCPS 5.0 - Sistema de carboidratos e proteínas líquidos para avaliação da nutrição de rebanhos e excreção de nutrientes: documentação do Modelo CNCPS. / FOX, D.G. et al. Tradução: LOPES, F.C.F. et al. Juiz de Fora: Embrapa Gado de Leite, 2003. 202p.

DETMANN, E.; PAULINO, M.F.; ZERVOUDAKIS, J.T. et al. Cromo e indicadores internos na determinação do consumo de novilhos mestiços, suplementados, a pasto. Revista Brasileira de Zootecnia, v.30, n.5, p.1600-1609, 2001.

DETMANN, E.; PAULINO, M.F.; CABRAL, L.S. et al. Simulação e validação de parâmetros da cinética digestiva em novilhos mestiços suplementados a pasto, por intermédio do sistema in vitro de produção de gases. Revista Brasileira de Zootecnia, v.34, n.6, p.2112-2122, 2005.

DETMANN, E.; SOUZA, A.L.; GARCIA, R. et al. Avaliação do "vício de tempo" de indicadores internos em ensaio de digestão com ruminantes. Arquivo Brasileiro de Medicina Veterinária e Zootecnia, v.59, n.1, p.182-188, 2007.
DETMANN, E.; PAULINO, M.F.; VALADARES FILHO, S.C. Avaliação nutricional de alimentos ou de dietas? Uma abordagem conceitual. In: SIMPÓSIO DE PRODUÇÃO DE GADO DE CORTE, 6., 2008, Viçosa, MG Anais... Viçosa, MG: SIMCORTE, 2008. p.21-51.

EZEQUIEL, J.M.B.; QUEIROZ, M.A.A.; GALATI, R.L. et al. Processamento da cana-de-açúcar: efeitos sobre a digestibilidade, o consumo e a taxa de passagem. Revista Brasileira de Zootecnia, v.34, n.5, p.1704-1710, 2005.

GARCIA, R.; NEIVA, J.N.M. Utilização da amonização na melhoria da qualidade de volumosos para ruminantes. In: SIMPÓSIO NORDESTINO DE ALIMENTAÇÃO DE RUMINANTES, 1994 Salvador. Anais... Salvador: 1994. p.41-57.

HADDAD, S.G.; GRANT, R.J.; KACHMAN, S.D. Effect of wheat straw treated with alkali on ruminal function and lactational performance of dairy cows. Journal of Animal Science, v.81, n.7, p.1956-1965, 1998.

HALL, M.B. Challenges with nonfiber carbohydrate methods Journal of Animal Science, v.81, n.12, p.3226-3232, 2003.

KOZLOSKI, G.V. Bioquímica dos ruminantes. Santa Maria: UFSM, 2002. 140p.

LICITRA, G.; HERNANDEZ, T.M.; VAN SOEST, P.J. Standardization of procedures for nitrogen fracionation of ruminant feed. Animal Feed Science Technological, v.57, n.4, p.347-358, 1996.

MERTENS, D.R. Gravimetric determination of amylase-treated neutral detergent fiber in feeds with refluxing in beakers or crucibles: collaborative study. Journal of AOAC International, v.85, p.1217-1240, 2002.

MORAES, K.A.K.; VALADARES FILHO, S.C.; MORAES, E.H.B.K. et al. Cana-de-açúcar tratada com óxido de cálcio fornecida com diferentes níveis de concentrado para novilhas de corte em confinamento. Revista Brasileira de Zootecnia, v.37, n.7, p.1293-1300, 2008

NATIONAL RESEARCH COUNCIL - NRC. Nutrient requirements of dairy cattle. 6.ed. Washinton, D.C.: National Academic Press, 1989. 157p.

NATIONAL RESEARCH COUNCIL - NRC. Nutrient requirements of dairy cattle. 7.ed. Washington, D.C.: National Academy Press, 2001. 450p.

NUSSIO, L.G.; LIMA, L.G.; MATTOS, W.R.S. Alimentos volumosos para o período da seca. In: SIMPÓSIO SOBRE MANEJO E NUTRIÇÃO DE GADO DE LEITE, 2000, Goiânia. Anais... Goiânia: CNBA, 2000. p.85-100.

NUSSIO, L.G.; SCHMIDT, P.; PEDROSO, A.F. Silagem de cana-deaçúcar. In: FORRAGICULTURA E PASTAGENS: TEMAS EM EVIDÊNCIA-SUSTENTABILIDADE, 1., 2003, Lavras. Anais... Lavras: UFLA, 2003. p.49-74.

OLIVEIRA, A.S. Casca de café ou casca de soja em substituição ao milho em dietas à base de cana-de-açúcar para vacas leiteiras. 2005. 97f. Dissertação (Mestrado em Zootecnia) Universidade Federal de Viçosa, Viçosa, MG.

PAULINO, M.F.; DETMANN, E.; VALADARES FILHO, S.C. Suplementação animal em pasto: energética ou protéica? In: SIMPÓSIO SOBRE MANEJO ESTRATÉGICO DA PASTAGEM, 3., 2006, Viçosa, MG. Anais... Viçosa, MG: SIMFOR, 2006. p.359-392.

PIRES, A.J.V.; GARCIA, R.; SOUZA, A.L. et al. Avaliação do consumo de silagens de sorgo tratadas com amônia anidra e, ou, sulfeto de sódio na alimentação de novilhas 3/4 Indubrazil/ Holandês. Revista Brasileira de Zootecnia, v.32, n.6, p.1525-1531, 2003.

PIRES, A.J.V.; GARCIA, R.; VALADARES FILHO, S.C. et al Novilhas alimentadas com bagaço de cana-de-açúcar tratado com amônia anidra e, ou, sulfeto de sódio. Revista Brasileira de Zootecnia, v.33, n.4, p.1078-1085, 2004.

PONTES, R.A.M. Cana-de-açúcar in natura ou ensilada com óxido cálcio e uréia em dietas de ovinos. 2007. 60f. Dissertação (Mestrado em Zootecnia) - Universidade Federal de Viçosa, Viçosa, MG. 
PRADO, I.N.; MOREIRA, F.B. Suplementação de bovinos no pasto e alimentos usados na bovinocultura. Maringá: UEM, 2002. 162p.

ROCHA JR., V.R.; VALADARES FILHO, S.C.; BORGES, A.M. et al. Estimativa do valor energético dos alimentos e validação das equações propostas pelo NRC (2001). Revista Brasileira de Zootecnia, v.32, n.2, p.480-490, 2003.

SILVA, D.J.; QUEIROZ, A.C. Análise de alimentos: métodos químicos e biológicos. Viçosa, MG: UFV, 2002. 235p.

SILVA, S.C. A cana-de-açúcar como alimento volumoso suplementar. In: PEIXOTO, A.M. et al. (Eds). Volumosos para bovinos. Piracicaba: FEALQ, 1993. p.59-74.

SNIFFEN, C.J.; O’CONNOR, D.J.; Van SOEST, P.J. et al. A net carbohydrate and protein system for evaluating cattle diets: carbohydrate and protein availability. Journal of Animal Science, v.70, n.12, p.3562-3577, 1992.

STATISTICAL ANALYSES SYSTEM - SAS. SAS user's guide. Cary: 1999. v.8, 295p.

VALADARES FILHO, S.C.; SILVA, P.A.; ROCHA JR., V.R. et al. Estimativa do valor energético dos alimentos em condições tropicais. In: VOLUMOSOS NA PRODUÇÃO DE RUMINANTES: VALOR ALIMENTÍCIO DE FORRAGENS, 1. 2003, Jaboticabal. Anais... Jaboticabal: Funep, 2003. p.71-86. VAN SOEST, P.J. Nutritional ecology of the ruminant. 2.ed. Ithaca: Cornell University Press, 1994. 476p.

WEISS, W.P. Energy prediction equations for ruminant feeds. In: CORNELL NUTRITION CONFERENCE FOR FEED MANUFACTURERS, 61., 1999, Ithaca. Proceedings... Ithaca: Cornell University, 1999. p.176-185. 